\title{
RESEARCH
}

\section{Impact of patient communication problems on the risk of preventable adverse events in acute care settings}

\author{
Gillian Bartlett PhD, Régis Blais PhD, Robyn Tamblyn PhD, Richard J. Clermont MD, \\ Brenda MacGibbon PhD
}

$\infty$

See related article page 1573

\section{ABSTRACT}

Background: Up to $50 \%$ of adverse events that occur in hospitals are preventable. Language barriers and disabilities that affect communication have been shown to decrease quality of care. We sought to assess whether communication problems are associated with an increased risk of preventable adverse events.

Methods: We randomly selected 20 general hospitals in the province of Quebec with at least 1500 annual admissions. Of the 145672 admissions to the selected hospitals in 2000/01, we randomly selected and reviewed 2355 charts of patients aged 18 years or older. Reviewers abstracted patient characteristics, including communication problems, and details of hospital admission, and assessed the cause and preventability of identified adverse events. The primary outcome was adverse events.

Results: Of 217 adverse events, 63 (29\%) were judged to be preventable, for an overall population rate of $2.7 \%$ (95\% confidence interval $[\mathrm{Cl}] 2.1 \%-3.4 \%$ ). We found that patients with preventable adverse events were significantly more likely than those without such events to have a communication problem (odds ratio [OR] 3.00; $95 \% \mathrm{Cl} 1.43-6.27$ ) or a psychiatric disorder (OR 2.35; 95\% Cl 1.09-5.05). Patients who were admitted urgently were significantly more likely than patients whose admissions were elective to experience an event (OR 1.64, 95\% Cl 1.07-2.52). Preventable adverse events were mainly due to drug errors ( $40 \%)$ or poor clinical management (32\%). We found that patients with communication problems were more likely than patients without these problems to experience multiple preventable adverse events ( $46 \%$ v. $20 \%$; $p=0.05$ ).

Interpretation: Patients with communication problems appeared to be at highest risk for preventable adverse events. Interventions to reduce the risk for these patients need to be developed and evaluated.

Une version française de ce résumé est disponible à l'adresse www.cmaj.ca/cgi/content/full/I78/I2/I555/DCI

CMAJ 2008;178(12):1555-62
$\mathrm{P}$ atient safety is a priority in modern health care systems. From $3 \%$ to $17 \%$ of hospital admissions result in an adverse event, ${ }^{1-8}$ and almost $50 \%$ of these events are considered to be preventable. ${ }^{3,0-12}$ An adverse event is an unintended injury or complication caused by delivery of clinical care rather than by the patient's condition. The occurrence of adverse events has been well documented; however, identifying modifiable risk factors that contribute to the occurrence of preventable adverse events is critical. Studies of preventable adverse events have focused on many factors, but researchers have only recently begun to evaluate the role of patient characteristics. ${ }^{2,9,12,13}$ Older patients and those with a greater number of health problems have been shown to be at increased risk for preventable adverse events. ${ }^{10,11}$ However, previous studies have repeatedly suggested the need to investigate more diverse, modifiable risk factors. ${ }^{3,6,7,10,11,14-16}$

Language barriers and disabilities that affect communication have been shown to decrease quality of care $;^{16-20}$ however, their impact on preventable adverse events needs to be investigated. Patients with physical and sensory disabilities, such as deafness and blindness, have been shown to face considerable barriers when communicating with health care professionals. ${ }^{20-24}$ Communication disorders are estimated to affect $5 \%-10 \%$ of the general population, ${ }^{25}$ and in one study more than $15 \%$ of admissions to university hospitals involved patients with I or more disabilities severe enough to prevent almost any form of communication. ${ }^{26}$ In addition, patients with communication disabilities are already at increased risk for depression and other comorbidities. ${ }^{27-29}$ Determining whether they are at increased risk for preventable adverse events would permit risk stratification at the time of admission and targeted preventive strategies.

We sought to estimate the extent to which preventable adverse events that occurred in hospital could be predicted by conditions that affect a patient's ability to communicate.

From the Department of Family Medicine (Bartlett), McGill University; the Department of Health Administration (Blais), Université de Montréal; the Departments of Medicine, and of Epidemiology and Biostatistics (Tamblyn), McGill University; the Département de médecine (Clermont), Centre hospitalier de l'Université de Montréal, Hôpital Hôtel-Dieu; and the Département de mathématiques (MacGibbon), Université du Québec à Montréal, Montréal, Que. 


\section{Methods}

\section{Study population}

All general acute care hospitals in the province of Quebec with a minimum of 1500 admissions per year and an emergency department were eligible to participate in our study if they were situated within $260 \mathrm{~km}$ of Montréal, the study coordinating centre (38.3\% of hospitals in the province). We classified hospitals as small (< roo beds), large ( $\geq$ roo beds, nonteaching) and teaching (university-based). We randomly selected a sample of 20 hospitals, which comprised 2 small, Io large and 8 teaching hospitals (each of the 4 faculties of medicine in Quebec are affiliated with 2 of the teaching hospitals). We sent a letter to the director general of each of the selected hospitals inviting the establishment to participate in the study. When a selected hospital refused to participate, another hospital was randomly selected from the same group. One teaching and 5 large hospitals refused to participate.

We compiled a list of eligible admissions from the Maintenance et exploitation des données pour l'étude de la clientèle hospitalière (Med-Echo) admission and discharge database in each hospital. We considered patients to be eligible for our chart review if they were 18 years of age or older; were admitted to hospital between Apr. I, 2000, and Mar. 3I, 200I; and were admitted to hospital for more than 24 hours or died within 24 hours after admission. We did not include patients whose discharge status was unknown or who were discharged alive within 24 hours after admission. We also excluded patients admitted because of primary obstetric or psychiatric reasons. Medical archivists from each hospital randomly selected charts from eligible admissions for review. If a patient had more than I admission during the year, we considered the first admission to be the index or study admission.

We obtained ethics approval for our study from the Université de Montréal Faculty of Medicine Research Ethics
Committee and from each of the hospitals participating in the study.

\section{Assessment of adverse events}

We used Baker and colleagues'1 definition of an adverse event: an unintended injury or complication caused by the delivery of clinical care rather than by the patient's underlying condition. We captured adverse events under 3 circumstances: those that occurred during the index admission; those that were caused by health care management provided within 12 months before the index admission and were detected during the index admission, regardless of where the care had been given (e.g., a patient with elective hip surgery who is readmitted I5 days after discharge with a surgical wound infection); and those that were caused by health care management and were detected within the 12 months after discharge from the index admission (Figure $\mathrm{I}$ ). We were not able to capture adverse events that occurred and were detected before the index admission, that occurred before the index admission but were only detected after discharge from the index admission, or that occurred and were detected after discharge from the index admission. We evaluated only admissions to participating hospitals. If patients were moved to an alternate level of care, we included them in our study as long as they remained in the same hospital.

We collected data through a 2-stage review of hospital charts using methods published in the Canadian Adverse Event Study. ${ }^{1}$ In the first stage, I of 6 trained research nurses abstracted patient data and assessed selected hospital charts against I8 screening criteria for an adverse event (Box I). In the second stage, I of 3 trained physician reviewers assessed each chart that met at least I screening criterion and classified the level of disability associated with each injury or complication recorded. The physician reviewer then assessed causation and preventability for each event to determine whether the injury or complication was an adverse event. The physician reviewers assessed causation using a 6-point scale, in

\begin{tabular}{|c|c|c|c|c|c|}
\hline & \multirow[b]{2}{*}{$\begin{array}{l}\text { Before index } \\
\text { admission }\end{array}$} & \multirow[b]{2}{*}{ Index admission } & \multirow[b]{2}{*}{$\begin{array}{l}\text { After index } \\
\text { admission }\end{array}$} & \multicolumn{2}{|c|}{ No. (\%) of adverse events } \\
\hline & & & & $\begin{array}{c}\text { Preventable } \\
n=63^{*}\end{array}$ & $\begin{array}{c}\text { Nonpreventable } \\
n=154 \dagger\end{array}$ \\
\hline \multirow{3}{*}{ 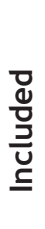 } & & $\mathrm{O} \longrightarrow \mathrm{D}$ & & $23(44.2)$ & $31(33.3)$ \\
\hline & 0 & $\longrightarrow \mathrm{D}$ & & $13(25.0)$ & $34(36.6)$ \\
\hline & & 0 & $\longrightarrow \mathrm{D}$ & $16(30.8)$ & $28(30.1)$ \\
\hline \multirow{2}{*}{ 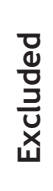 } & $\mathrm{O} \longrightarrow \mathrm{D}$ & & & - & - \\
\hline & 0 & 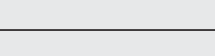 & $\longrightarrow$ D & - & - \\
\hline
\end{tabular}

Figure 1: Relation between index admission and occurrence (O) and detection (D) of adverse events over time. *Information was available to determine the period of capture for 52 of 63 preventable adverse events and $\dagger_{93}$ of 154 nonpreventable adverse events. 
which I indicated no evidence of health care management as the cause and 6 indicated certain evidence of health care management as the cause. We considered injuries and complications with a rating of 4 or higher (more than likely) to be adverse events. Physician reviewers assessed preventability using a similar 6-point scale; we considered an adverse event with a rating of 4 or higher to be preventable. ${ }^{1}$

For each adverse event, the physician reviewer assessed the patient's level of physical impairment at the time of discharge attributable to the adverse event. The physician reviewer then noted the department where the adverse event occurred and the primary factor that led to it, recording the event into one of the following mutually exclusive categories: diagnosis, surgery, fracture, anesthesia, medical procedure, drug or fluid, clinical management, system event, or other adverse event. We defined poor clinical management as a therapeutic ad-

Box 1: Screening criteria used to detect potential adverse events among patients admitted to hospital

- Unplanned admission (including readmission) as a result of health care management within the 12 months before the index admission

- Unplanned admission to any hospital within the 12 months after discharge from the index admission

- Hospital-incurred patient injury (including any harm, injury or trauma occurring during the index admission)

- Adverse drug reaction

- Unplanned transfer from general care to intensive care

- Unplanned transfer to another acute care hospital (excluding transfers for tests, procedures or specialized care that was not available at referring hospital)

- Unplanned return to the operating room

- Unplanned removal, injury or repair of organ or structure during surgery or invasive procedure

- Other patient complications (e.g., acute myocardial infarction, cerebrovascular accident, pulmonary embolism)*

- Development of neurological deficit not present at the time of admission but present at the time of discharge from the index admissiont

- Unexpected death

- Inappropriate discharge to home or inadequate discharge plan for index admission (excluding discharges "against medical advice")

- Cardiac arrest or respiratory failure

- Injury related to abortion or to labour and delivery

- Hospital-acquired infection or sepsisł

- Dissatisfaction with care documented in the medical record or evidence of complaint lodged

- Documentation or correspondence indicating litigation, either contemplated or actual

- Any other undesirable outcomes not covered above

*Includes any unexpected complication occurring during the index admission that is not a natural progression of the patient's disease or an expected outcome of treatment.

tIncludes neurological deficits related to procedures, treatments or investigations.

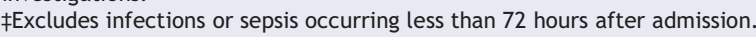

verse event (e.g., inappropriate treatment, a delay in treatment, failure to monitor the patient's condition).

We assessed interrater agreement for the first stage of the review at each hospital by reabstracting and blindly reassessing $10 \%$ of all charts submitted to the nurse reviewers. For the second stage, the 2 physicians at each site separately reviewed the charts that were positive for at least I screening criterion. One of the 2 physicians then finalized the review in conjunction with a senior physician.

\section{Abstraction of patient characteristics}

Nurse reviewers collected information on patient communication disorders or problems, psychosocial factors, comorbidities, disabilities, age, sex and admission characteristics before assessing the chart against the criteria indicating a potential adverse event. We used a Charlson Comorbidity Index score to summarize comorbidities. ${ }^{30}$ The information we recorded about patient communication problems included evidence that the patient experienced difficulty with communication; whether the source of the problem was language, a physical problem or was undetermined; and whether the patient was blind, deaf or had other physical disabilities that were judged to interfere with communication. Psychosocial factors that might also affect communication included the presence of a social distancing problem (e.g., alcoholism, drug abuse, homelessness) or a secondary diagnosis of a psychiatric disorder (e.g., depression, anxiety). We recorded whether the index admission was urgent or elective, and whether the admitting hospital was a small, large or teaching hospital.

\section{Statistical analysis}

We calculated population-weighted point estimates and confidence intervals (CIs) for adverse events using the 2-stage review $^{1}$ described in the section on the assessment of adverse events. We assessed interrater agreement by calculating the kappa score. ${ }^{31}$ For patients with multiple injuries or complications, we used the most serious one to determine the characteristics of the adverse event. We performed a multiple logistic regression analysis using generalized estimated equations to assess patient predictors for preventable adverse events, adjusting for the clustering of patients admitted to the same hospital. ${ }^{32}$ We sorted by date of admission and used generalized estimating equations to account for the correlation that may have been introduced into the data for patients admitted on the same day or in the same month. ${ }^{33}$ We controlled for confounding due to other factors that have been shown to be statistically significant for patients experiencing preventable events (e.g., age, sex, comorbidities, admission characteristics). We used a $\chi^{2}$ test to determine the preventability of adverse events among patients with and without communication problems for different outcomes, including multiple injuries or complications, prolonged hospital stay, hospital readmission and the presence of communication problems at the time of discharge. We also performed the Fisher exact test to determine whether there was a statistically significant association between communication problems and preventable adverse events. 


\section{Results}

Of the 145672 eligible admissions in the 20 participating hospitals, we reviewed 2355 charts, which accounted for $98 \%$ of our random sample of 2409 admissions (Table r). We excluded charts if they contained insufficient documentation. A total of 584 charts met at least I criterion for a preventable adverse event, and the physician reviewers identified 377 injuries or complications in 292 patients (Figure 2). Physician reviewers considered the injuries or complications of 2 I 7 patients to be adverse events, for a populationweighted point estimate of $8.5 \%$ (95\% CI $7.2 \%-9.8 \%$ ). We judged the adverse events experienced by $63(29 \%)$ of these patients to be preventable, for an overall rate of $2.7 \%(95 \%$ CI 2.I $\%-3.4 \%$ ). The relation between index admission and the detection of preventable adverse events in these patients is shown in Figure $\mathrm{I}$.

The kappa score for interrater agreement in the first stage of the review by the research nurses was 0.70 (95\% CI $0.62-0.78$ ), which indicated moderately high reliability. Our sensitivity analysis showed no significant change in the results if we moved the cut-off rating for causation and preventability from 4 or higher (more than likely) to 5 or higher (moderate to strong evidence). Therefore, we left the cut-off rating at 4 or higher.

A greater proportion of patients with physical communication problems, psychiatric disorders and comorbidities had preventable adverse events than patients without those challenges. In addition, preventable adverse events occurred more often among women than among men. They also occurred more often among patients 65 years or older than among younger patients. The mean age of the 63 patients who experienced a preventable adverse event was 65.9 (standard deviation [SD] $\mathrm{r} 6.5$ ); the mean age of the 2138 patients with no adverse events was 6r.7 (SD I8.o) (Table 2).

The presence of a physical communication problem was significantly associated with an increased risk of experiencing a preventable adverse event (odds ratio [OR] 3.97; $p=0.004$ ) (Table 3). Similarly, the presence of a psychiatric disorder was significantly associated with an increased risk of a preventable adverse event (OR 2.44; $p=0.029$ ) (Table 3). This association held after we adjusted for other patient and admission characteristics (Figure 3 and Table 3). In addition, patients who were admitted to hospital on an urgent basis had a significantly in-

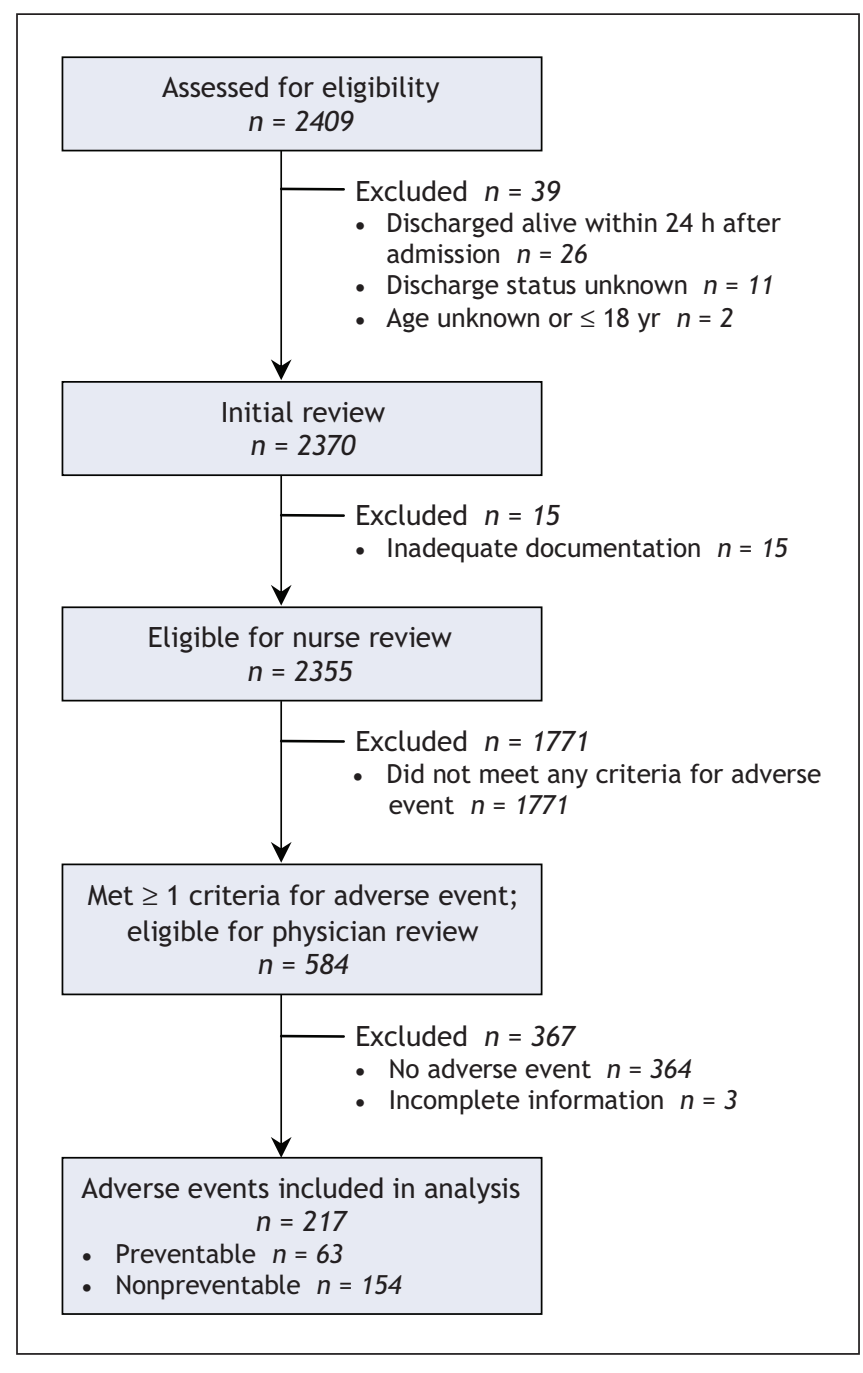

Figure 2: Selection of medical charts screened for the occurrence of a preventable adverse event.

Table 1: Characteristics of acute care hospitals in Quebec, Canada, and charts assessed for preventable adverse events

\begin{tabular}{|c|c|c|c|c|}
\hline \multirow[b]{2}{*}{ Characteristic } & \multicolumn{4}{|c|}{ Type of hospital, ${ }^{*}$ no. (\%) } \\
\hline & $<100$ beds & $\geq 100$ beds & Teaching $†$ & All \\
\hline Eligible hospitals & $24(29.6)$ & $39(48.1)$ & $18(22.2)$ & $81(100.0)$ \\
\hline Hospitals participating in the study & $2 \quad(8.0)$ & $10(26.0)$ & $8(44.0)$ & $20 \quad(25.0)$ \\
\hline $\begin{array}{l}\text { Total eligible admissionsł to participating } \\
\text { hospitals from Apr. 1, 2000, to Mar. 31, } \\
2001\end{array}$ & $31798 \quad(7.4)$ & $223949(51.8)$ & $176161(40.8)$ & $431908(100.0)$ \\
\hline Charts reviewed & $286 \quad(0.9)$ & $1132(0.5)$ & $937 \quad(0.5)$ & 2355 \\
\hline
\end{tabular}

*Random selection of acute care hospitals within $260 \mathrm{~km}$ of Montréal, Quebec (research centre), with at least 1500 inpatient admissions per year and a 24-hour emergency department. We excluded specialty hospitals.

†Hospital with full-time residency training programs in medicine and surgery.

$\ddagger$ We considered patients 18 years and older who had a minimum admission of 24 hours, or who died within 24 hours after admission to be eligible. We excluded admissions for which the primary diagnosis was related to obstetrics or psychiatry. 
creased risk of experiencing a preventable adverse event compared with patients whose admissions were elective.

We found that $57 \%(n=36)$ of patients who experienced a preventable adverse event received treatment or an intervention with sequelae. The most common sequelae were prolonged hospital stays (35\%), readmission to hospital (32\%) and discharge with minimal impairment or recovery within I month (Io\%). A small percentage of patients with preventable adverse events experienced moderate impairment with recovery in I year $(5 \%)$, experienced permanent impairment $(3 \%)$ or died (6\%). Multiple preventable adverse events occurred more frequently among patients with a psychiatric disorder or a physical communication problem compared with patients without these factors ( $46 \%$ v. $20 \% ; p=0.05$ ). A smaller percentage of patients with these 2 factors than without them had a prolonged hospital stay ( $8 \%$ v. $42 \% ; p=0.02)$.

We assessed the sources of the most severe adverse events for 57 of 63 patients whose charts contained adequate information. The majority of severe preventable adverse events were drug related $(40 \%)$ or caused by poor clinical management $(32 \%) ; 18 \%$ were due to anesthesia, surgery or medical procedures. The differences in source ( $p$ values $0.46-0.8 \mathrm{I}$ ) and type ( $p$ values $0.08-0.29$ ) of preventable adverse events between patients with and those without a physical communication problem or psychiatric disorder were not statistically significant. Among patients with a documented communication problem, the source tended to be physical challenges such as deafness ( 5 of 7 patients with communication challenges) rather than problems related to spoken language. Of the patients with either a communication problem or psychiatric disorder who experienced a preventable adverse event, 7 of 13 patients spoke neither French nor English. The most common psychiatric disorder was depression ( 6 of 7 patients); the remaining disorders included anxiety, dementia, personality disorder, panic attacks, schizophrenia and psychosis.

\section{Interpretation}

We found that patients with communication problems were 3 times more likely to experience a preventable adverse event than patients without such problems. These events were mainly drug related or caused by poor clinical management. Almost half of the events were associated with some level of disability or multiple hospital admissions, with one-third of the patients who experienced preventable adverse events requiring readmission to hospital. These results emphasize the importance of providing additional resources for these patients to improve patient safety.

Our findings build on those of earlier studies concerning patient communication and quality of health care. ${ }^{21-23}$ In a large North American survey, Iezzoni and colleagues ${ }^{22}$ found that participants with any major disability affecting communication were more likely than patients without such disabilities to be dissatisfied with physicians' understanding of their conditions and with the time spent discussing their problems and answering questions. Participants who were deaf or hard of hearing reported that they were very con-

Table 2: Patient and admission characteristics, by status of adverse event

Status of adverse event; no. (\%) of patients

\begin{tabular}{|c|c|c|c|}
\hline Characteristic & $\begin{array}{c}\text { Preventable } \\
n=63\end{array}$ & $\begin{array}{c}\text { Nonpreventable } \\
n=154\end{array}$ & $\begin{array}{c}\text { No adverse event } \\
n=2138\end{array}$ \\
\hline \multicolumn{4}{|l|}{ Patient } \\
\hline $\begin{array}{l}\text { Physical communication } \\
\text { problem* }\end{array}$ & 7 (11)ף & $4 \quad(3)$ & $65 \quad(3)$ \\
\hline Psychiatric disordert & 7 (11)ף & $6 \quad(4)$ & $104 \quad(5)$ \\
\hline Social distancing problem $\ddagger$ & 3 (5) & $5 \quad(3)$ & $108 \quad(5)$ \\
\hline $\begin{array}{l}\text { Charlson Comorbidity Index } \\
\text { score }>1 \S\end{array}$ & $22(35)$ & $42(27)$ & $479(22)$ \\
\hline Female sex & 37 (59) & 72 (47) & 1055 (49) \\
\hline$>65 \mathrm{yr}$ & $39(62)$ & $82(53)$ & $1073(50)$ \\
\hline \multicolumn{4}{|l|}{ No. of comorbidities } \\
\hline 0 & $14(22)$ & $28(18)$ & $621(29)$ \\
\hline $1-5$ & $38(60)$ & $115(75)$ & $1415(66)$ \\
\hline $6-10$ & $11(18)$ & 11 (7) & 102 (5) \\
\hline \multicolumn{4}{|l|}{ Admission } \\
\hline Urgent admission & $53(84)$ & $110(71)$ & $1576(74)$ \\
\hline Teaching hospital & $24(38)$ & $78(51)$ & 835 (39) \\
\hline
\end{tabular}

*Includes documented communication difficulties, blindness and deafness.

tIncludes diagnoses for depression and other psychiatric disorders.

flncludes alcoholism, drug abuse and homelessness.

$\S$ Charlson Comorbidity Index score was categorized at the 75th percentile of the distribution of the index.

$\mathbb{\eta} p<0.01$ by Fisher exact test for comparison with nonpreventable adverse events. 
cerned with medication safety and other risks associated with inadequate communication, as well as communication problems during medical procedures. ${ }^{21}$ The results of a study by
Steinberg and colleagues ${ }^{23}$ involving 54 deaf patients indicated that the minimal level of communication they have with health professionals would not be tolerated by hearing pa-

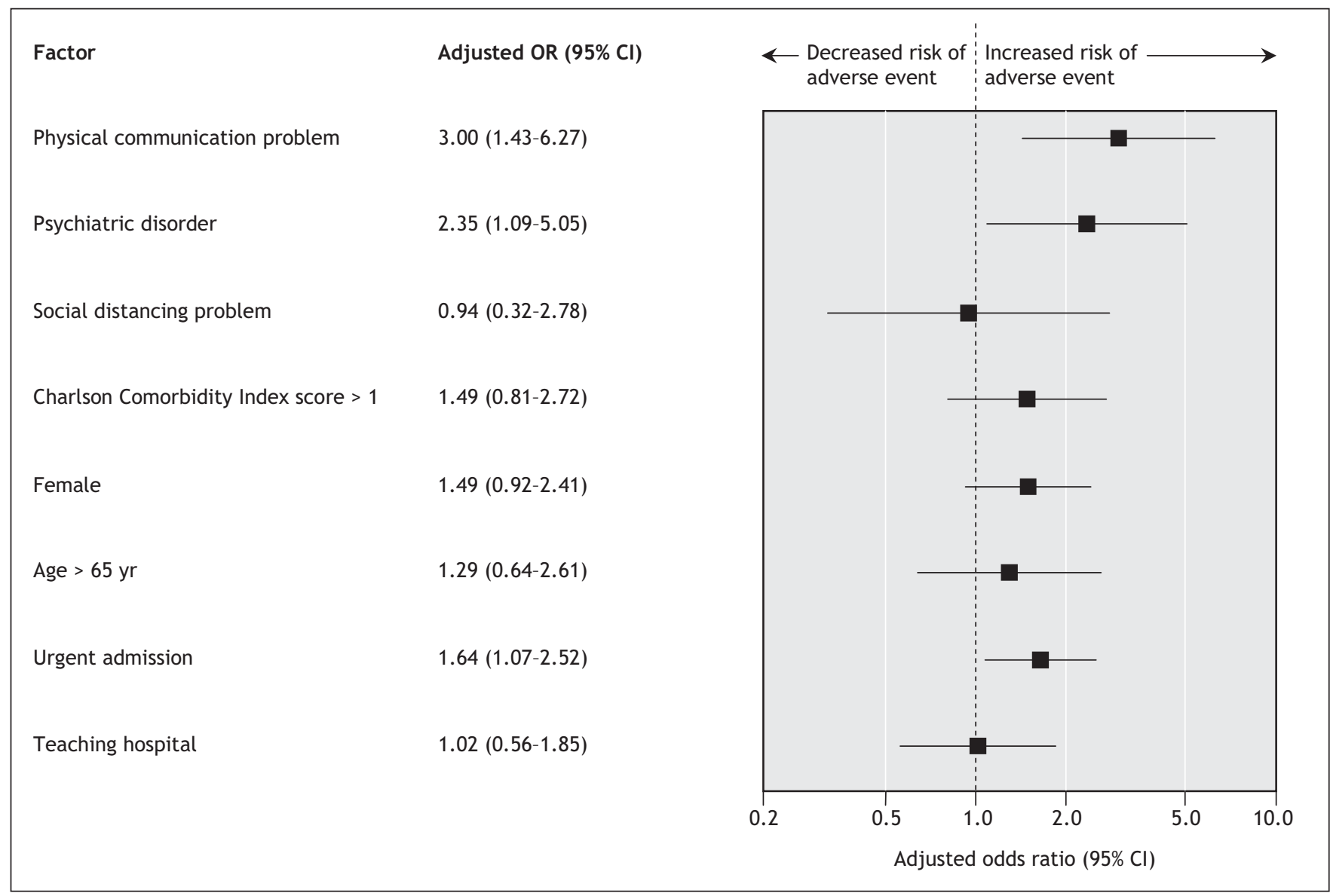

Figure 3: Odds ratios (ORs) and $95 \%$ confidence intervals (Cls) for factors associated with preventable adverse events, adjusted for age, sex, Charlson Comorbidity Index score, admission status and type of hospital.

Table 3: Unadjusted and adjusted odds ratios in multivariable regression evaluating patient and hospital characteristics associated with preventable adverse events

\begin{tabular}{llll}
\hline Characteristic & Unadjusted OR $(95 \% \mathrm{Cl})$ & Adjusted OR* $(95 \% \mathrm{Cl})$ & $p$ value \\
\hline Patient & & $3.00(1.43-6.27)$ & 0.004 \\
\hline Physical communication problem† & $3.97(2.04-7.71)$ & $2.35(1.09-5.05)$ & 0.029 \\
\hline Psychiatric disorderł & $2.44(1.20-4.97)$ & $0.94(0.32-2.78)$ & 0.92 \\
\hline Social distancing problem§ & $0.94(0.33-2.68)$ & $1.49(0.81-2.72)$ & 0.19 \\
\hline Charlson Comorbidity Index score $>19$ & $1.84(1.10-3.09)$ & $1.49(0.92-2.41)$ & 0.11 \\
\hline Female sex & $1.45(0.94-2.24)$ & $0.64-2.61)$ & \\
\hline$>65$ yr & $1.63(0.88-3.00)$ & $1.64(1.07-2.52)$ \\
\hline Admission & & $1.02(0.56-1.85)$ \\
\hline Urgent admission & $1.89(1.22-2.93)$ & 0.023 \\
\hline Teaching hospital & $0.96(0.53-1.72)$ & 0.96 \\
\hline
\end{tabular}

Note: $\mathrm{Cl}=$ confidence interval, $\mathrm{OR}=$ odds ratio.

*Adjusted for age, sex, Charlson Comorbidity Index score, urgent v. elective admission and teaching v. nonteaching hospital.

tIncludes documented communication difficulties, blindness or deafness.

†Includes diagnoses for depression and other psychiatric disorders.

§Includes alcoholism, drug abuse and homelessness.

ףCharlson Comorbidity Index score was categorized at the 75th percentile of the distribution of the index. 
tients. In our study, half of the communication problems recorded were due to deafness, and most of the preventable adverse events were drug related or caused by poor clinical management (e.g., inappropriate treatment, delay in treatment, failure to monitor the patient's status). These types of errors relate to the concerns raised by deaf patients about inadequate communication.

Although the studies involving deaf patients ${ }^{22,23}$ did not specifically target hospital settings, the issues they raised are supported by findings of a study by Azoulay and colleagues ${ }^{18}$ about communication between physicians and families of patients in an intensive care unit. The authors found that factors such as foreign country of origin $(p=0.007)$ and unfamiliarity with the official language $(p=0.03)$ were associated with poor comprehension of diagnosis, prognosis and treatment: in $33 \%$ of cases, patient representatives were from foreign countries, and in $\mathrm{I} 6 \%$ of cases they did not speak English or French. Although we did not specifically examine ethnic background as a potential communication barrier, in our study only $17 \%$ of the patients with a communication problem spoke $\mathrm{I}$ of the 2 official languages.

Our study is a retrospective chart review and, as such, has important limitations. First, chart reviews capture documented adverse events; however, they do not capture events that are rectified before any resulting injuries or complications occur. As a result, the rates of preventable adverse events are probably underestimated..$^{34-36}$ To capture more potential adverse events, we did not require that the adverse event result in hospital readmission, permanent disability or death. $^{15,34}$

Second, our chart review relied on the judgment of the physician and nurse reviewers, as well as the quality of the original charting. Our study achieved moderately high reliability, with kappa scores that were equivalent or better than those reported in studies using similar methodology. ${ }^{1,3-6}$ Communication disabilities are estimated to occur in $5 \%-10 \%$ of the general population and in up to $15 \%$ of hospital admissions. ${ }^{20,26}$ Therefore, our finding that $3 \%$ of our population had a documented communication barrier indicates that these disabilities may not have been systematically charted.

Third, our results are based on a limited number of preventable adverse events and a limited number of patients with communication problems. Despite the small numbers, we documented a 3 -fold increase in risk that was both statistically and clinically significant. Furthermore, the number of preventable adverse events recorded in our study was similar to that found in previous studies of adverse events completed in Canada ${ }^{1,2}$ and Britain. ${ }^{8}$ Our analysis adjusted for many of the other potential predictors of preventable adverse events. Therefore, our finding that the risk of a preventable adverse event is 3 times higher among patients with a communication problem than among patients without such problems remains robust and may be conservative.

To improve patient safety, a prospective controlled evaluation of the health care experience of patients with and without communication problems should be conducted. Clinicians and patients have proposed strategies for improving communication and optimizing the flow of information between the patient and the health care team..$^{21,22,26}$ The impact of these proposed strategies on reducing the number of preventable adverse events and their impact on provision of care should be evaluated from the patient's perspective. Once the impact of interventions on preventable adverse events is assessed, patients with communication challenges can be identified at the time of admission to ensure they receive safe care. ${ }^{20,37}$ Our study was not designed to provide insight into how or why the presence of communication problems increases the occurrence of preventable adverse events. Therefore, it is important for future research to investigate interpersonal dynamics that may be responsible. This research will become critical as the number of adults with disabilities affecting communication increases as the elderly population increases.

This article has been peer reviewed.

Competing interests: None declared.

Contributors: Gillian Bartlett contributed to the study conception and design, the analysis and interpretation of the data, and the drafting and final revision of the manuscript. Régis Blais contributed to the study conception and design, the acquisition and interpretation of the data, the critical revision of the manuscript and the acquisition of funding for the study. Robyn Tamblyn contributed to the study conception and design, the analysis and interpretation of the data, the critical revision of the manuscript and the acquisition of funding for the study. Richard Clermont contributed to the study conception and design, the acquisition of the data, the critical revision of the manuscript and the training of physician and nurse reviewers. Brenda MacGibbon contributed to the statistical analyses and the critical revision of the manuscript. All of the authors approved this version of the manuscript. Gillian Bartlett had full access to all of the data in the study and takes responsibility for the integrity of the data and the accuracy of the data analysis.

Acknowledgements: Data collection for this study was funded by the Canadian Institute for Health Information, the Canadian Institutes of Health Research and the Ministère de la santé et des services sociaux. Gillian Bartlett is supported by a career award from the Fonds de recherche en santé du Québec. Robyn Tamblyn is a Canadian Institute for Health Information Scientist.

\section{REFERENCES}

I. Baker GR, Norton PG, Flintoft V, et al. The Canadian Adverse Events Study: the incidence of adverse events among hospital patients in Canada. CMAJ 2004; $170: 1678-86$.

2. Forster AJ, Asmis TR, Clark HD, et al. Ottawa Hospital Patient Safety Study: incidence and timing of adverse events in patients admitted to a Canadian teaching hospital. CMAJ 2004;170:1235-40.

3. Davis $\mathrm{P}$, Lay-Yee R, Briant R, et al. Adverse events in New Zealand public hospitals. I: occurrence and impact. NZ Med J 2002;II5:U27I.

4. Thomas EJ, Studdert DM, Burstin HR, et al. Incidence and types of adverse events and negligent care in Utah and Colorado. Med Care 2000;38:26I-7I.

5. Wilson R, Runciman WB, Gibberd RW, et al. The quality in Australian Health Care Study. Med J Aust 1995;163:458-71.

6. Brennan TA, Leape LL, Laird NM, et al. Incidence of adverse events and negligence in hospitalized patients: results of the Harvard Medical Practice Study I. N Engl Med I991;324:370-6.

7. Woods D, Thomas E, Holl J, et al. Adverse events and preventable adverse events in children. Pediatrics 2005;II5:I55-60.

8. Vincent C, Neale G, Woloshynowych M. Adverse events in British hospitals: preliminary retrospective record review. BMJ 200I;322:517-9.

9. Leape LL, Brennan TA, Laird N, et al. The nature of adverse events in hospitalized patients: results of the Harvard Medical Practice Study II. $N$ Engl J Med I99I; 324:377-84.

Io. Davis P, Lay-Yee R, Briant R, et al. Preventable in-hospital medical injury under the "no fault" system in New Zealand. Qual Saf Health Care 2003;I2:25I-6.

II. Thomas EJ, Brennan TA. Incidence and types of preventable adverse events in elderly patients: population based review of medical records. BMJ 2000;320:74I-4

I2. Leape LL, Lawthers AG, Brennan TA, et al. Preventing medical injury. Qual Rev Bul I993;I44-I49. 
I3. Petersen LA, Brennan TA, O'Neil AC, et al. Does housestaff discontinuity of care increase the risk for preventable adverse events? Ann Intern Med 1994;121:866-72.

I4. Kable AK, Gibberd RW, Spigelman AD. Adverse events in surgical patients in Australia. Int J Qual Health Care 2002;14:269-76.

15. Weingart SN, Wilson RM, Gibberd RW, et al. Epidemiology of medical error. BMJ 2000;320:774-7.

I6. Vincent CA, Coulter A. Patient safety: What about the patient? Qual Saf Health Care 2002;1I:76-80.

I7. Kuzel AJ, Woolf SH, Gilchrist VJ, et al. Patient reports of preventable problems and harms in primary health care. Ann Fam Med 2004;2:333-40.

18. Azoulay E, Chevret S, Leleu G, et al. Half the families of intensive care unit patients experience inadequate communication with physicians. Crit Care Med 2000;28:3044-9.

19. Green CA, Pope CR. Gender, psychosocial factors and the use of medical services: a longitudinal analysis. Soc Sci Med I999;48:1363-72.

20. Hoffman JM, Yorkston KM, Shumway-Cook A, et al. Effect of communication disability on satisfaction with health care: a survey of Medicare beneficiaries. Am J Speech Lang Pathol 2005;14:221-8.

2I. Iezzoni LI, O'Day BL, Killeen M, et al. Communicating about health care: observations from persons who are deaf or hard of hearing. Ann Intern Med 2004; I40:356-62.

22. Iezzoni LI, Davis RB, Soukup J, et al. Quality dimensions that most concern people with physical and sensory disabilities. Arch Intern Med 2003;163:2085-92.

23. Steinberg AG, Sullivan VJ, Loew RC. Cultural and linguistic barriers to menta health service access: the deaf consumer's perspective. Am J Psychiatry 1998;155:982-4.

24. Dalton DS, Cruickshanks KJ, Klein BEK, et al. The impact of hearing loss on quality of life in older adults. Gerontologist 2003;43:66I-8.

25. Ruben RJ. Redefining the survival of the fittest: communication disorders in the 2Ist century. Laryngoscope 2000;IIO:24I-5.

26. Ebert DA, Heckerling PS. Communication disabilities among medical inpatients. NEngl J Med 1998;339:272-3.

27. Strawbridge WJ, Wallhagen MI, Shema SJ, et al. Negative consequences of hearing impairment in old age: a longitudinal analysis. Gerontologist 2000;40:320-6.

28. Turner RJ, Noh S. Physical-disability and depression - a longitudinal analysis. $J$ Health Soc Behav I988;29:23-37.

29. Prince MJ, Harwood RH, Blizard RA, et al. Impairment, disability and handicap as risk factors for depression in old age. The Gospel Oak Project. 5. Psychol Med I997;27:3II-2I.

30. Charlson ME, Pompei P, Ales KL, et al. A new method of classifying prognostic comorbidity in longitudinal studies: development and validation. J Chronic Dis I987;40:373-83.

3I. Landis JR, Koch GG. Measurement of observer agreement for categorical data. Biometrics 1977;33:159-74.

32. Liang KY, Zeger SL. Longitudinal data analysis using generalized linear models. Biometrics 1986;73:13-22.

33. Jennrich RI, Schluchter MD. Unbalanced repeated-measures models with structured covariance matrices. Biometrics I986;42:805-20.

34. Leape LL. Error in medicine. JAMA I994;272:185I-7.

35. Forster AJ, Shojania KG, van Walraven C. Improving patient safety: moving beyond the "hype" of medical errors. CMAJ 2005;173:893-4.

36. Brennan TA, Localio AR, Leape LL, et al. Identification of adverse events occurring during hospitalization - a cross-sectional study of litigation, quality assurance, and medical records at 2 teaching hospitals. Ann Intern Med I990;II2:22 I-6.

37. Ford JD, Trestman RL, Steinberg K, et al. Prospective association of anxiety, depressive, and addictive disorders with high utilization of primary, specialty and emergency medical care. Soc Sci Med 2004;58:2145-8.

Correspondence to: Dr. Gillian Bartlett, 515-517 Pine Ave. W, Montréal, QC H2W IS4; fax 514 398-4202; gillian.bartlett@mcgill.ca 